\title{
Fast tooth root load capacity optimization based on improved design of hob geometry
}

\author{
Ray Uelpenich ${ }^{1 *}$ and Peter Tenberge ${ }^{1}$ \\ ${ }^{1}$ Ruhr Universität Bochum, Chair of Industrial and Automotive Drivetrains, 44801 Bochum, Germany
}

\begin{abstract}
The competitiveness of gearboxes is significantly influenced by their performance ability. Increasing the tooth root load capacity has always been in focus of current research because in case of a failure of the gearwheel due to a tooth root fracture, the complete gearbox fails. This paper presents a new calculation method that enables the optimization of hob geometries within a few minutes so that they lead to reduced stresses in the tooth root fillet of spur gears. This results in reductions of the maximum tooth root stress of $10 \%$ and more for most gearwheels. The manufacturing costs for the optimized hob are only influenced slightly. In order to increase the computational speed compared to purely FE-based optimization methods, the present paper shows a method in which the decisive part of the optimization process is based on an analytical equation which are derived by a small number of FE-calculations.
\end{abstract}

\section{Introduction}

Spur gears are one of the most important machine elements and essential in so many applications. The further development of gearboxes is always focused on improvement in order to make them lighter, more efficient and more powerful. Thereby, also the guarantee of low manufacturing costs is a significant factor.

The performance and durability of spur gears is limited by various types of damage. These include micro-pitting, pitting, abrasion, scuffing, flank fracture and tooth root fracture. The tooth root fracture in particular plays a major role, because it causes immediate gearbox failure. Previous solutions to increase the tooth root load capacity can be divided into 3 groups: materials, manufacturing processes and tooth root geometry. These include the development of new materials that are purer and finer-grained $[1,2]$, the improvement of manufacturing processes for example in order to specifically introduce residual compressive stresses into the component surface $[3,4]$ or to improve the heat treatment $[5,6]$ and the modification of the tooth root geometry to reduce tooth root stresses [7-12]. In particular, the geometric design of the tooth root has a high potential for increasing the tooth root load carrying capacity.

Conventional design methods for spur gears are based on calculation rules that are only valid for standardized gearwheel geometries [13, 14]. When using gearwheels with non-standardized geometries, some assumptions of the standard are invalid. The maximum stress which is relevant for the calculation of the tooth root load capacity does no longer arise at the $30^{\circ}$ tangent of the tooth root fillet, as it is firmly assumed in the standards. For this reason, the standardized calculation rules are no longer valid and other calculation methods must be used. By using computer-aided analysis methods such as the Finite Element Method (FEM) or the Boundary Element Method (BEM), it is possible to make detailed observations to the stresses on the tooth. Based on these results better tooth root geometries can be developed which lead to reduced tooth root stresses.

Within the scope of research activities, there are currently various methods for optimizing the tooth root geometry based on FE-calculations. Different models are used to describe the tooth root geometry parametrically. In order to find the tooth root geometry, which leads to a minimum tooth root stress respectively a maximum tooth root load capacity, these parameters are varied. The resulting tooth geometry is analysed using FEcalculations until the ideal contour is found. For the execution of such an optimization process, a large amount of FE-calculations is required, which leads in many cases to a total optimization time of several hours or days.

This paper shows a simulation method for the optimization of the tooth root geometry of spur gears milled by a hob. The significant part of the optimization process for this method is based on an analytical equation derived from only a small number of FEcalculations. Thus, the calculation time for an optimization process can be reduced to a few minutes compared to a method purely based on FE-calculations, without any losses in optimization potential.

A further focus of the presented optimization process is to ensure economical gearwheel manufacturing by gear hobbing compared to the expensive production by 5 -axis milling or profile grinding. For this reason, geometry optimization in the context of this method does not directly affect the tooth root fillet of the spur gear,

Corresponding author: ray.uelpenich@rub.de 
but the contour of a hob. A gear hob simulation finally leads to the tooth geometry of the finished gearwheel. The optimized tooth root geometry achieved in this way has the same optimization potential compared to a direct optimization of the tooth root. This is shown by comparative calculations with optimization results from other research projects. It also can be recognized by the fact that the tooth root stresses within the optimized tooth root fillet are constant over a large section.

\section{Basics}

The production of spur gears by hobbing is a highly productive and cost-effective process. Therefore, the aim of the presented optimization method is to adapt the hob geometry in such a way that the tooth root fillet of a spur gear produced with this hob exhibits lower maximum marginal stresses.

The hob contour is defined in analogy to DIN 3960 [15] as a rack, as shown in Figure 1 below. The rack is divided into a tip and a root area along the profile reference line $\mathrm{P}$ and consists of several sections.

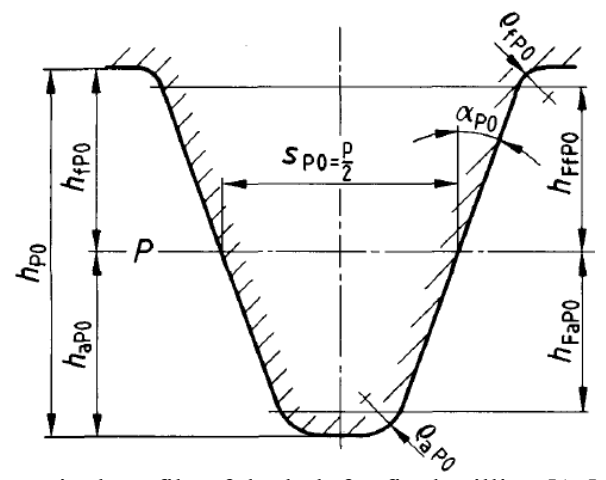

Fig. 1. Nominal profile of the hob for final milling [15].

The linear part of the hob generates the effective involute flank of the spur gear teeth between the tip diameter $d_{a}$ and the root form diameter $d_{F f}$. The subsequent tooth root fillet between the root form diameter $d_{F f}$ and the root diameter $d_{f}$ is defined by the hob tip corner geometry and the hobbing movement during the milling process. Figure 2 and Figure 3 illustrate how the final contour of the gearwheel results from the enveloping condition of the individual overlaid contours during the hobbing movement between the hob and the gearwheel blank.

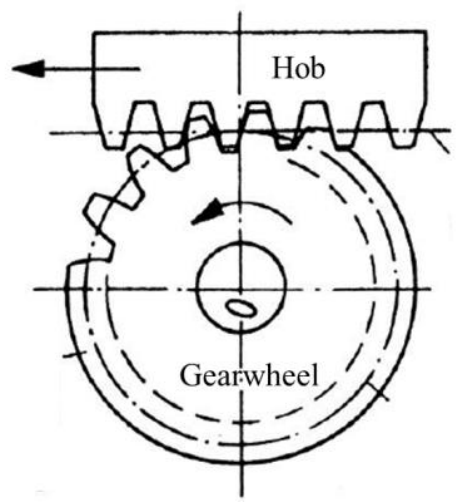

Fig. 2. Generation of teeth by a hobbing movement between hob and gearwheel blank.

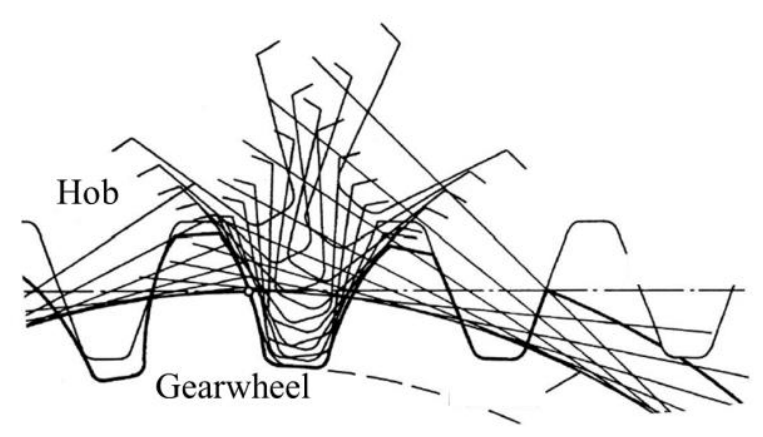

Fig. 3. Generation of the final tooth contour by the envelopecutting condition.

DIN 867 [16] specifies the nominal profile for the manufacture of spur gears with conventional contours. The tip corner geometry of the tool is designed with a constant curved radius. With such a defined tool, different tooth geometries can be created, which still makes their application very economical today.

A design of the tool tip geometry contour that differs from the DIN-standard allows to create tooth root curves with extremely low maximum tooth root stresses. The optimization of the tool contour is already practiced in many cases today. However, all methods presented in other research projects so far require a very long computing time in order to achieve an optimized contour. In the following, a calculation method is presented which makes it possible to achieve the same results in the optimizations in only a few minutes.

\section{Potential to reduce the max. tooth root stress through an optimum hob contour}

The following considerations focus on explaining the optimization potential of the spur gear tooth variants listed in Table 1 and 2. All results listed in the following are based on a nominal tooth force of $F_{n}=55 \mathrm{kN}$ affecting on the outer single contact point at the diameter $d_{e}=132.3 \mathrm{~mm}$.

Table 1. Data of the example gearwheel (Part1).

\begin{tabular}{|l|l|c|c|}
\hline Description: & Sign: & \multicolumn{2}{|c|}{ Variant: } \\
\hline Geometry: & & $\mathbf{1}$ & $\mathbf{2}$ \\
\hline Number of teeth & $z$ & \multicolumn{2}{|c|}{21} \\
\hline Normal module & $m_{n}$ & \multicolumn{2}{|c|}{$6 \mathrm{~mm}$} \\
\hline Normal Pressure angle & $\alpha_{n}$ & \multicolumn{2}{|c|}{$22^{\circ}$} \\
\hline Helix angle & $\beta$ & \multicolumn{2}{|c|}{$0^{\circ}$} \\
\hline Profile shift coefficient & $x^{*}$ & \multicolumn{2}{|c|}{0.302} \\
\hline Tip alteration of gear & $k$ & $-0.014 \mathrm{~mm}$ \\
\hline Facewidth & $b$ & $72 \mathrm{~mm}$ \\
\hline Reference diameter & $d$ & $126 \mathrm{~mm}$ \\
\hline Center distance & $a$ & $211 \mathrm{~mm}$ \\
\hline Addendum coefficient & $h^{*}{ }_{a P}$ & \multicolumn{2}{|c|}{1} \\
\hline Dedendum coefficient & $h^{*}{ }_{f P}$ & \multicolumn{2}{|c|}{1.25} \\
\hline Tip radius coefficient & $\rho^{*}{ }_{f P}$ & 0.38 & 0.42 \\
\hline
\end{tabular}


Table 2. Data of the example gearwheel (Part2).

\begin{tabular}{|l|l|c|}
\hline Description: & Sign: & Value: \\
\hline Loads: & & \\
\hline Torque & $T$ & $2571 \mathrm{Nm}$ \\
\hline Application factor & $K_{A}$ & 1.25 \\
\hline $\begin{array}{l}\text { Outer single contact } \\
\text { diameter }\end{array}$ & $d_{e}$ & $132.3 \mathrm{~mm}$ \\
\hline Load application angle & $\alpha_{e}$ & $24.372^{\circ}$ \\
\hline Material: & & \\
\hline Modulus of elasticity & $E$ & $206 \mathrm{GPa}$ \\
\hline Poisson's ratio & $v$ & 0.3 \\
\hline
\end{tabular}

The assessment of the tooth root stress as a consequence of a changed tooth root geometry is based on the main tensile stress. As shown in Figure 4, only a part of the calculated gearwheel segment is loaded with the main tensile stresses relevant for the tooth root load carrying capacity. Therefore, the results of the FEcalculations explained below are displayed within the area of the tooth root fillet marked in red.

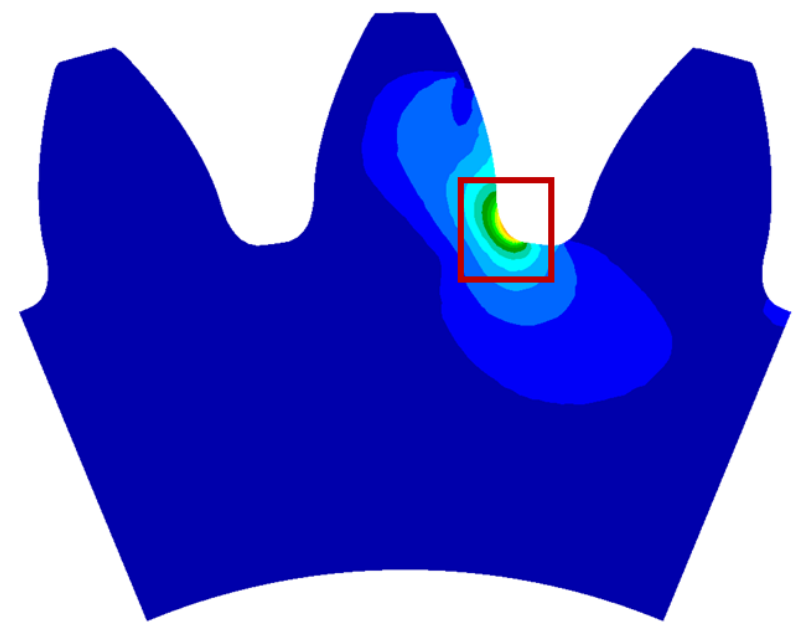

Fig. 4. Main stress in the gearwheel segment of the standard version according to variant 1 .

In the first version of the gearwheel shown in Table 1 and 2 (variant 1) describes the reference gearwheel. This standard profile corresponds to the requirements of DIN 867, where the tip corner of the hob is designed as a radius. The root radius factor corresponds to $\rho_{f P}^{*}=0.38$. As shown in Figure 5a) a maximum main stress of $\sigma_{\text {Ref }}=287 \mathrm{MPa}$ calculated with FEM is obtained for this version. In the following, this value is used as a reference value in relation to which all stress reductions achieved by the other designs and optimizations of the hob geometry are indicated.

If an optimization of the tooth root geometry is performed under the condition that the position of the root form diameter $d_{F f}$ is not change, the stress in the tooth root is reduced by approximately $11 \%$ to a value of $\sigma=255 \mathrm{MPa}$ as shown in Figure 5b).

If the tooth root radius factor can be increased to the maximum possible value of $\rho_{f P}^{*}=0.42$ in accordance with variant 2 of the gearwheel geometry, compared with the reference value the stress is reduced by approximately $2 \%$ to $\sigma=280 \mathrm{MPa}$ as shown in Figure 5c). Using the optimization process this value can be reduced up to $\sigma=249 \mathrm{MPa}$ which is corresponding to a stress reduction of approximately $13 \%$.

In a third variant of the gearwheel geometry a stress reduction of approximately $3 \%$ to $\sigma=277 \mathrm{MPa}$ can be achieved by using the maximum tooth root fillet which is limited by the active root diameter $d_{N f}$ and the root diameter $d_{f}$ (Figure 5e). The tip corner of the hob is designed as a radius. By optimizing the tip contour of the hob, the stress value in the tooth root compared to the reference value can be reduced by approximately $17 \%$ to $\sigma=238 \mathrm{MPa}$.

This demonstrates that by applying an optimization process to the hob (and thus to the tooth root contour) compared to a tool contour designed according to DIN 3972 [17] considerable reductions of the main stresses occurring in the root of the teeth can be achieved.

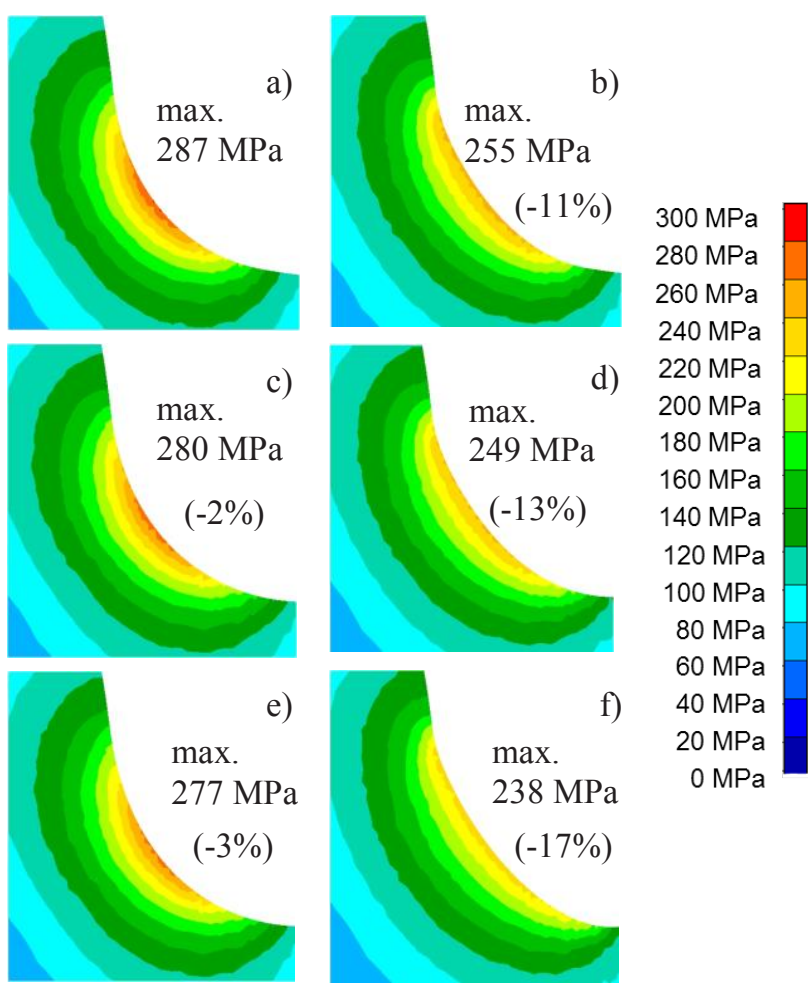

Fig. 5. Main stresses for different designs of the tooth root geometry.

Figure 6 gives an overview of the changes in the tooth root fillet with regard to the tooth designs described above. This shows that an optimized tooth root geometry compared to a conventional design of the profile according to DIN 867 has form deviations of about $m_{n} / 100$ to $m_{n} / 30$. 


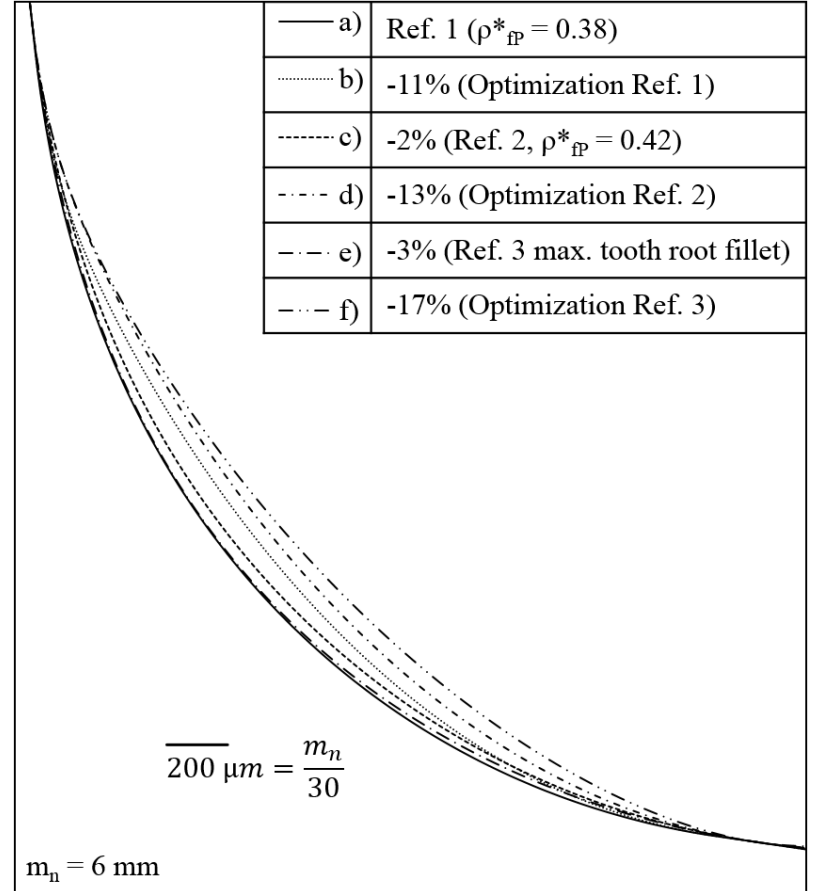

Fig. 6. Different types of tooth root geometry

Due to the fact that the optimization process in the methodology presented is based on an adaptation of the tip contour of the hob, it is possible to display the contour of the hob that leads to the optimized tooth root geometry. Figure 7 shows the tip corner contours of the hob for the spur gear designs described above. In analogy to the considerations of the modified tooth root fillets, the contour changes of the tip corner of a nonoptimized tool compared to an optimized variant are also in the range of approximately $m_{n} / 100$ to $m_{n} / 30$. Hence, the adjustment $m_{n} / 100$ in the adaptation of the tip corner geometry for an optimized hob correspond to dimensions similar to those tools which are usually used for the modulation of conventional tooth corrections.

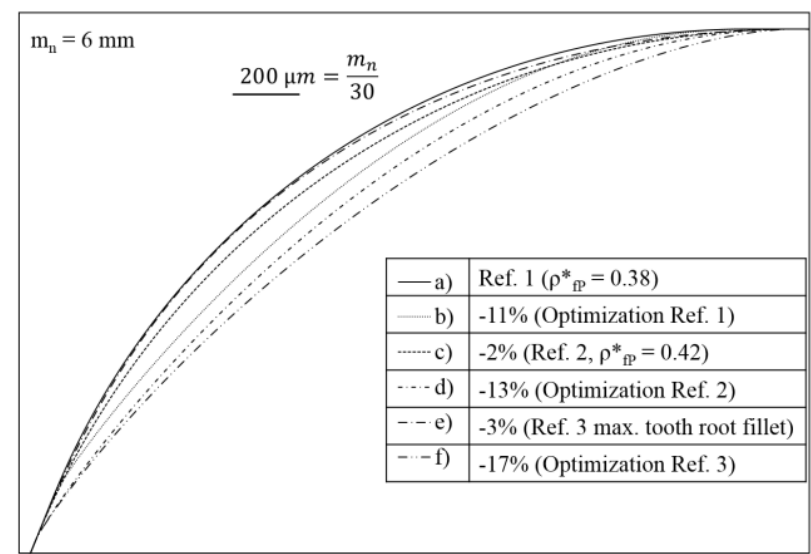

Fig. 7. Different versions of the tip corner geometry of the hob

The FE-based optimization of the tooth root contour offers a further advantage in the utilization of the performance potential of a gearing, which is not immediately apparent at first glance. Therefore, the calculation of the tooth root stress according to the standard calculation procedure partly shows higher stress values than determined with FEM. This results in lower tooth root stress safety for a gearing with the same load due to the application of standard calculation methods. These differences occur especially with gearwheels where the tooth data differ from the nominal profile specified in DIN 867. Thereby the nominal pressure angle $\alpha_{n}$ plays a particular role. When the difference $\left|\alpha_{n}-20^{\circ}\right|$ is greater, the deviation $\left|\sigma_{F E M}-\sigma_{D I N}\right|$ is also higher. The use of FE-calculations to determine the stresses occurring in the tooth root is therefore not only a tool for calculating gearwheels that do not correspond to the standard profile, it is also suitable for fully exploiting the performance potential of a gearwheel.

\section{Method for fast tooth root optimization via adapted hob contours}

The tooth root optimization is performed in the presented method by adjusting the tip corner contour of the hob. In order to enable optimization within a few minutes various steps are needed. These are described in the following.

\subsection{Define hobbing tool}

In order to optimize the tooth root geometry of a spur gear all technically significant gearing data regarding the pinion and the mating gearwheel must be known. The data of the mating gearwheel are used to ensure the running capability before and after the optimization process. Furthermore, the position and magnitude of the effective load for the calculation result from the consideration of the tooth contact.

At the beginning of the optimization the gear hob contour is derived from the given gear tooth data as a gear rack which leads to a preliminary or final gear tooth. As shown in Figure 8 the tool can be defined with protuberances for subsequent fine machining in analogy to DIN 3960. Irrespective of whether the hob is a preliminary or a final milling cutter, it generates the contour of the tooth root fillet of the spur gear. In order to be able to manipulate the tooth root geometry the tip corner contour of the hob is represented by a Béziercurve defined by 5 parameters.

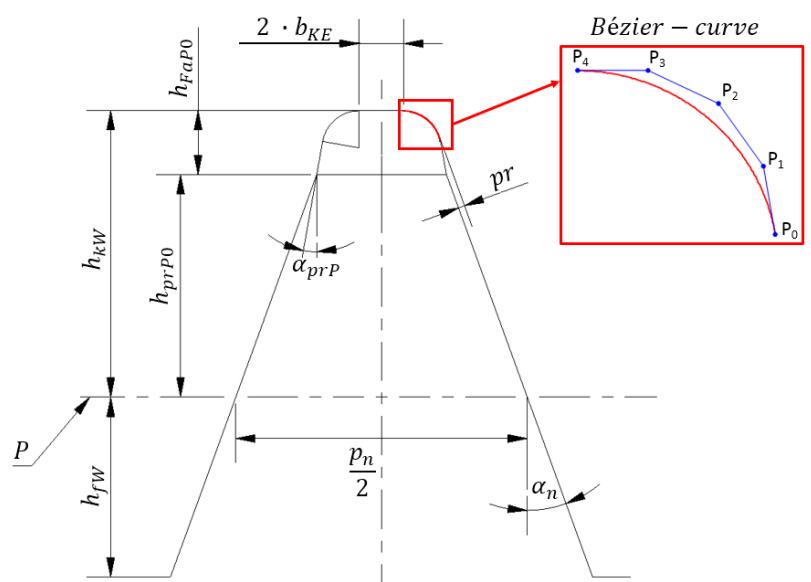

Fig. 8. A segment on the hob tip radius replaced by a Béziercurve.

By defining the parameters of the Bézier-curve, it is not only possible to display a curve with a constant 
radius of curvature, but also to describe any other shape (see Figure 9). The Bézier-curve always guarantees a tangential connection between the tip corner and the adjacent part of the hob geometry. In addition, it runs continuously between the start and end points. Therefore, the Bézier-curve is ideal for individually defining the tip corner contour of the hob as part of the optimization process. The Bézier-curve is defined by the following equation:

$\operatorname{Bezier}(\mathrm{P}, \mathrm{t}):=\sum_{\mathrm{k}=0}^{\mathrm{n}}\left[\frac{\mathrm{n} !}{\mathrm{k} ! \cdot(\mathrm{n}-\mathrm{k}) !} \cdot \mathrm{t}^{\mathrm{k}} \cdot(1-\mathrm{t})^{\mathrm{n}-\mathrm{k}} \cdot \mathrm{P}_{\mathrm{k}}\right]$

In this context, $\boldsymbol{P}$ describes the direction vector of the respective number of $\mathrm{n}$ points. The variable $t$ represents a point on the Bézier-curve and ranges from $0<t<1$.

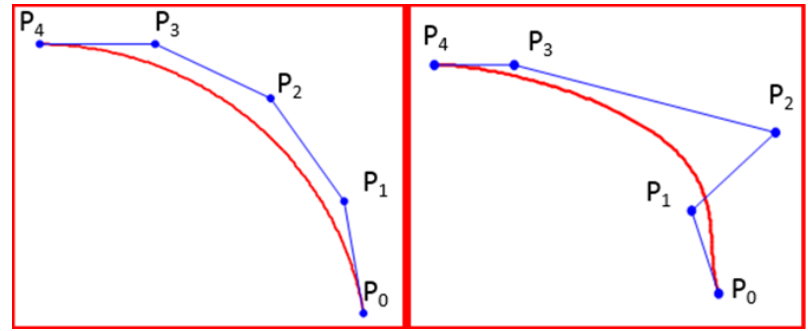

Fig. 9. Different Bézier-curve to describe tip radius of hob.

For each derivation of the hob geometry from the specified spur gear the maximum tip corner radius that can be achieved is also determined. In order to increase the range of the tooth root fillet further and thereby increase the optimization potential to reduce the tooth root stresses, the transition point from the tip corner geometry of the hob to the adjacent geometry can also be shifted. This is done until the tooth root form diameter $d_{F f}$ of the spur gear is close to the active root diameter $d_{N f}$.

\subsection{Hobbing simulation for fast generation of the tooth geometry}

In order to derive the geometry of the spur gear from the previously defined hobbing tool a hobbing simulation must be performed in the next step. For a very fast hobbing simulation, the gearwheel blank is represented as a material volume to be milled (see Figure 10 and Figure 11 magenta lines). The hob is shown as a rack consisting of several sections (see Figure 10 and Figure 11 black lines). Within the simulation of the gear hobbing process the simultaneous translatory movement of the gear rack and the rotational movement of the material volume are performed step by step (see Figure 10 and Figure 11, which show two different gearwheel positions). In addition, the position of the point of intersection between the sections of the rack and the lines describing the material volume is determined in each contact position. The points of intersection represent the geometry of the tooth gap that is created in the respective step of the hobbing process. A very fast hobbing simulation requires the fast determination of the many intersection points. To do this the intersection points in the central position between the hob and the material volume are determined first, because there are definite intersection points here. Starting from this position, the tool moves to the beginning and to the ending of the meshing whereby the search for the new intersection points always starts near to the intersection points that were found previously. The search ends as soon as no new points of intersection are found. This searching algorithm ensures that the number of calculation steps for determining the intersection points is reduced to a minimum so that the hobbing process, which runs many times as part of the entire optimization process, requires less calculation time.

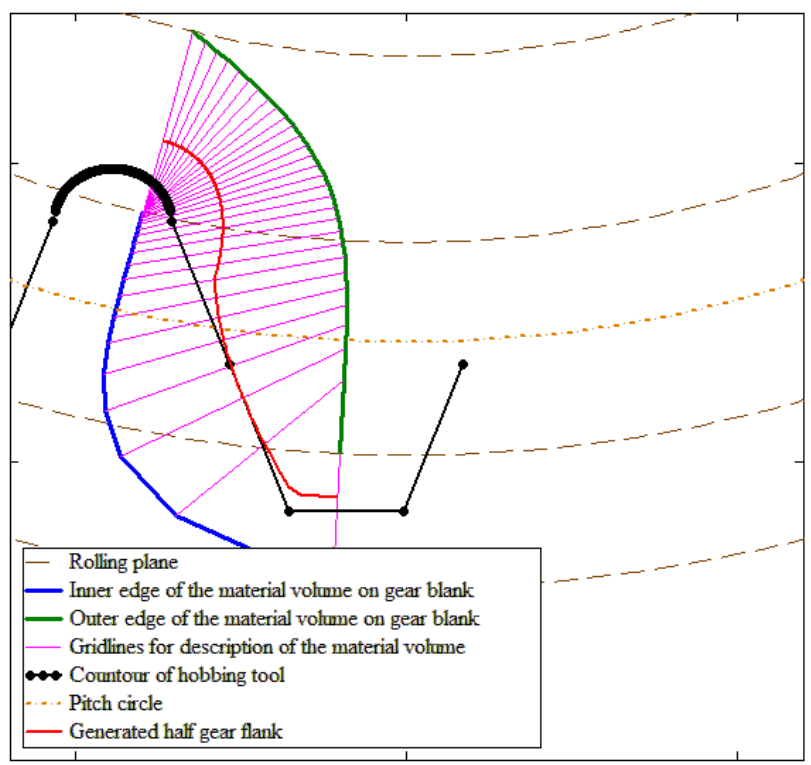

Fig. 10. Simulation of Hobbing process (Position 1).

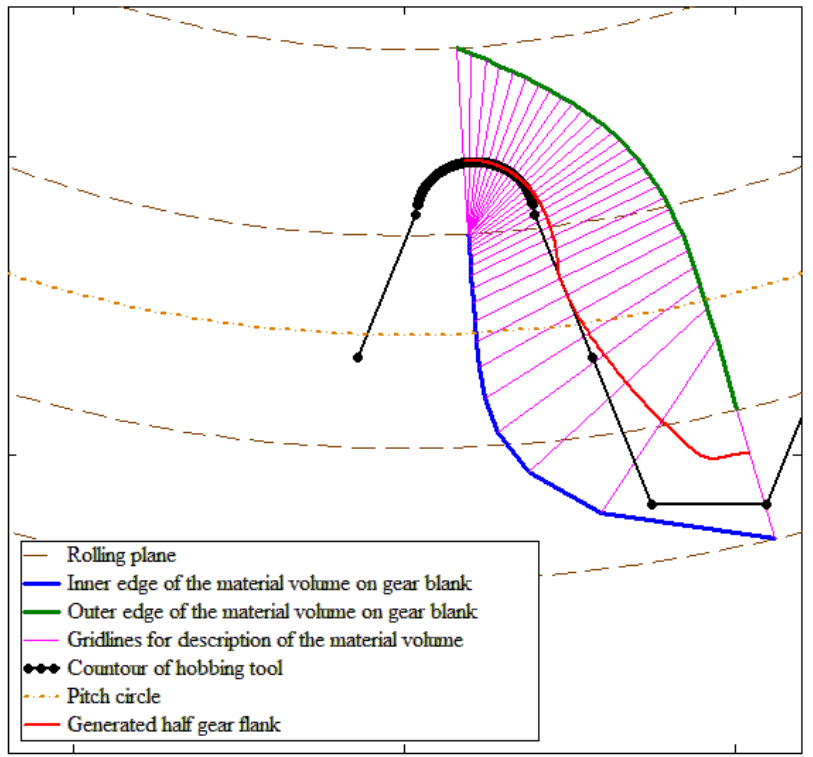

Fig. 11. Simulation of Hobbing process (Position 2).

The final contour of the tooth gap results from the enveloping condition of the individual intersection points found in the corresponding hobbing positions (see Figure 12). In this way, the tooth root geometry of the spur gear is created from the tip corner contour of the hob by performing the hobbing process. It can be influenced by modifying the parameters of the Béziercurve, which describes the tip contour of the hob. This 
algorithm can even be used to generate tooth root geometries with an extreme undercut.

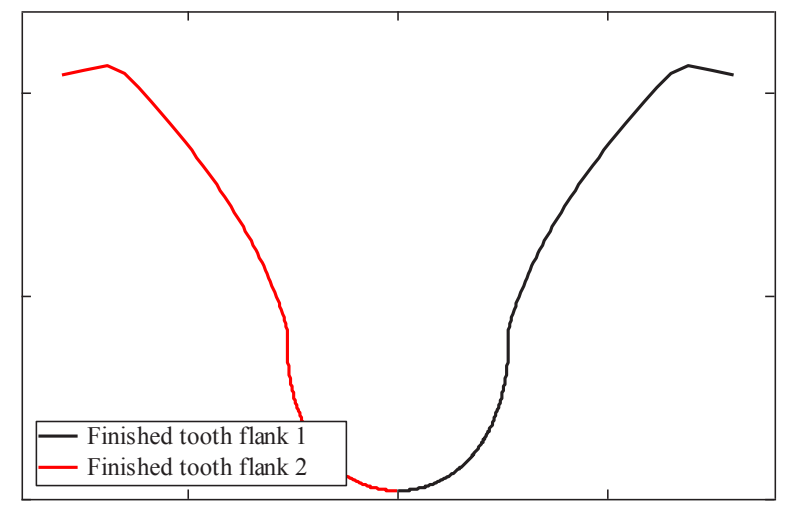

Fig. 12. Generated flanks.

Because only the tip corner couture of the hob and therefore the tooth root fillet of the spur gear change during the optimization process the hobbing simulation is limited to the tooth root area to increase the calculation speed. The other part of the tooth flank is adopted unchanged.

\subsection{Fast generation of a FE mesh}

Although the presented optimization process calculates the main steps on the basis of an analytical equation single FE-calculations are necessary. These results are used to determine the parameters for defining the analytical equation. Based on the contour of the spur gear, a plane FE model is created. As shown in Figure 13 the tooth root stress is calculated using a gearwheel segment consisting of 3 teeth. Due to the irregular geometry of the gearwheel segment, a meshing with the element types Triangular is performed. To improve the quality of the FE-calculation the tooth root fillet, which has the relevant main tensile stresses in the geometry optimization, is particularly tightly meshed. The gearwheel segment is fixed at the side and at the bottom margin in all directions. The application of the normal tooth force $F_{n}$ at the middle tooth lies at an application angle $\alpha_{e}$ on the outer single contact point with a diameter $d_{e}$.

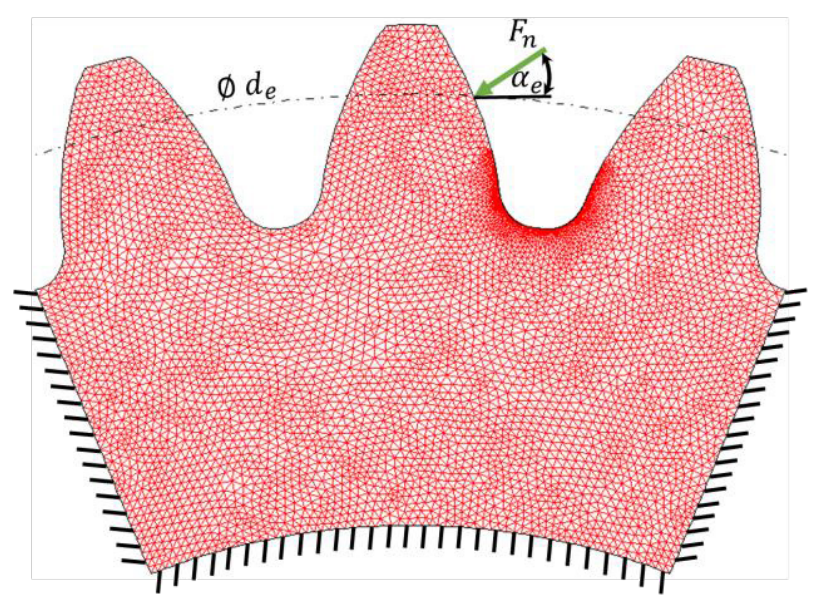

Fig. 13. Meshed segment before solving process.
Generating a similar FE mesh with conventional FE tools requires very high computing times. Therefore, a mesh adaptation is performed within the presented optimization process on the basis of a good reference mesh. To map the reference mesh to different gearing geometries, a fast adaptation procedure based on the mapping rule takes place. At the beginning of the adaptation process, the reference mesh is subdivided into the nodes and elements located at the margin of the tooth segment. Afterwards, in a first adaptation, the polar coordinates of all mesh nodes are adapted to the new maximum radii and angles of the tooth segment with the new tooth geometry. During a second adaptation, the angular coordinates are adjusted further to take the actual flank angles into account. After this adaptation, the position of the nodes on the upper margin of the FE mesh already agrees quite closely with the tooth geometry from the hobbing process. Within a third adaptation, all other nodes of the tooth segment are moved. To do this, the position of the nodes of the reference mesh located within the tooth segment is described by a new coordinate system defined by the upper and lower margin of the tooth segment (see Figure 14). The same coordinates of the notes of the reference mesh will be used for the nodes between the new margins. This routine and the new upper margin are used to finally position all nodes. In this way, a new FE mesh is generated. Because the modifications of the spur gear geometry are quite small compared to the reference mesh and all elements of the FE mesh are modified, the deformation of the individual elements is very small so that there are no significant changes in mesh quality.

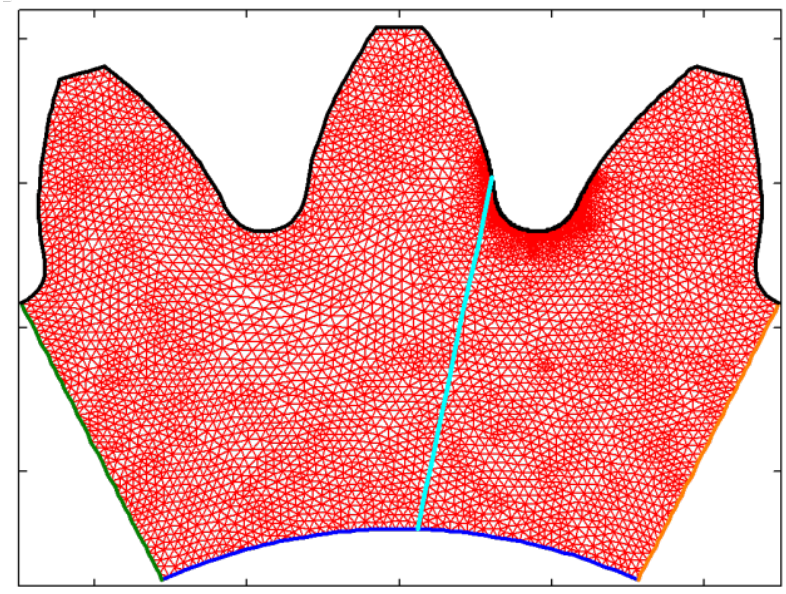

Fig. 14. Determination of the coordinates of the nodes in the third adaptation step.

Compared to conventional tools for tooth root optimization, which generate a new FE mesh for each new tooth geometry, the mesh adaptation used in the presented methodology needs far less computation time.

\subsection{Optimization algorithm}

The optimization of the tooth root geometry to reduce the tooth root stresses and increase the tooth root load capacity is currently in focus of many different research projects. In order to increase the computational speed for 
the performance of an optimization process in comparison to optimization processes based purely on FE results, a method will be presented below whereby the significant part of the optimization process is based on an analytical equation.

As shown in Figure 15 the first step in this process is to define a few different hob tip corner geometries which generate as many different curvature ratios as possible in the tooth root on the one hand and on the other hand are as close as possible to the optimum geometry. The use of results of earlier optimizations saved in databases helps to find a good starting solution and further reduce the computing times needed to perform the optimization process.

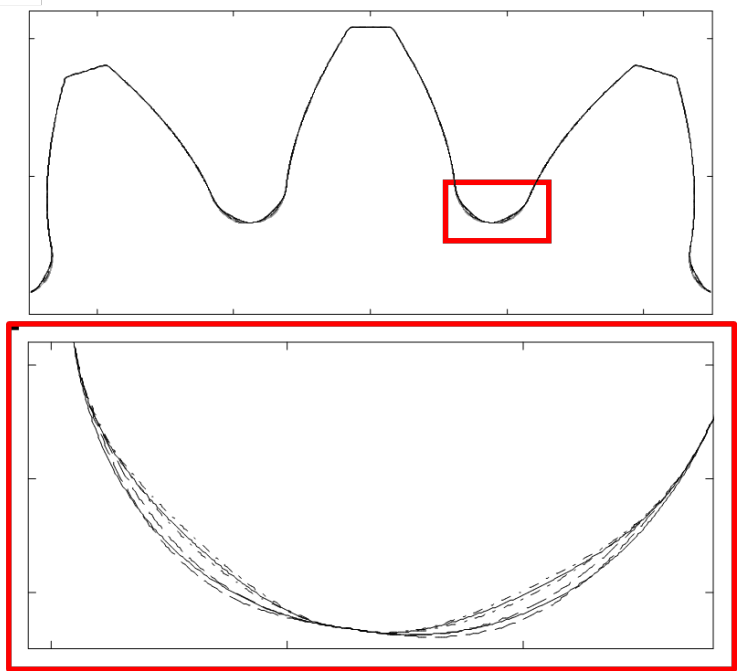

Fig. 15. Execution of different tooth root geometries to determine the analytical equation.

By performing FE-calculations for these first tooth root geometries different curves of the maximum principal stresses at the margin of the tooth root fillet, occur. Thereby the marginal stresses from the FEcalculation are smoothed first for further calculation, because they are partly liable for great fluctuations. The ratio at every point of the tooth root fillet between the maximum principal stress resulting from the FEcalculations to the nominal stress curves represents the form factor curve. According to the fundamentals of mechanics, the form factor depends on the discontinuity of the shape, which is primarily described by the size and curvature of notches. The result for a tooth root profile shown in Figure 16 clearly shows that the marginal stresses resulting from the FE-analyses are subject to big fluctuations and that locally bigger curvatures lead to higher stress values.
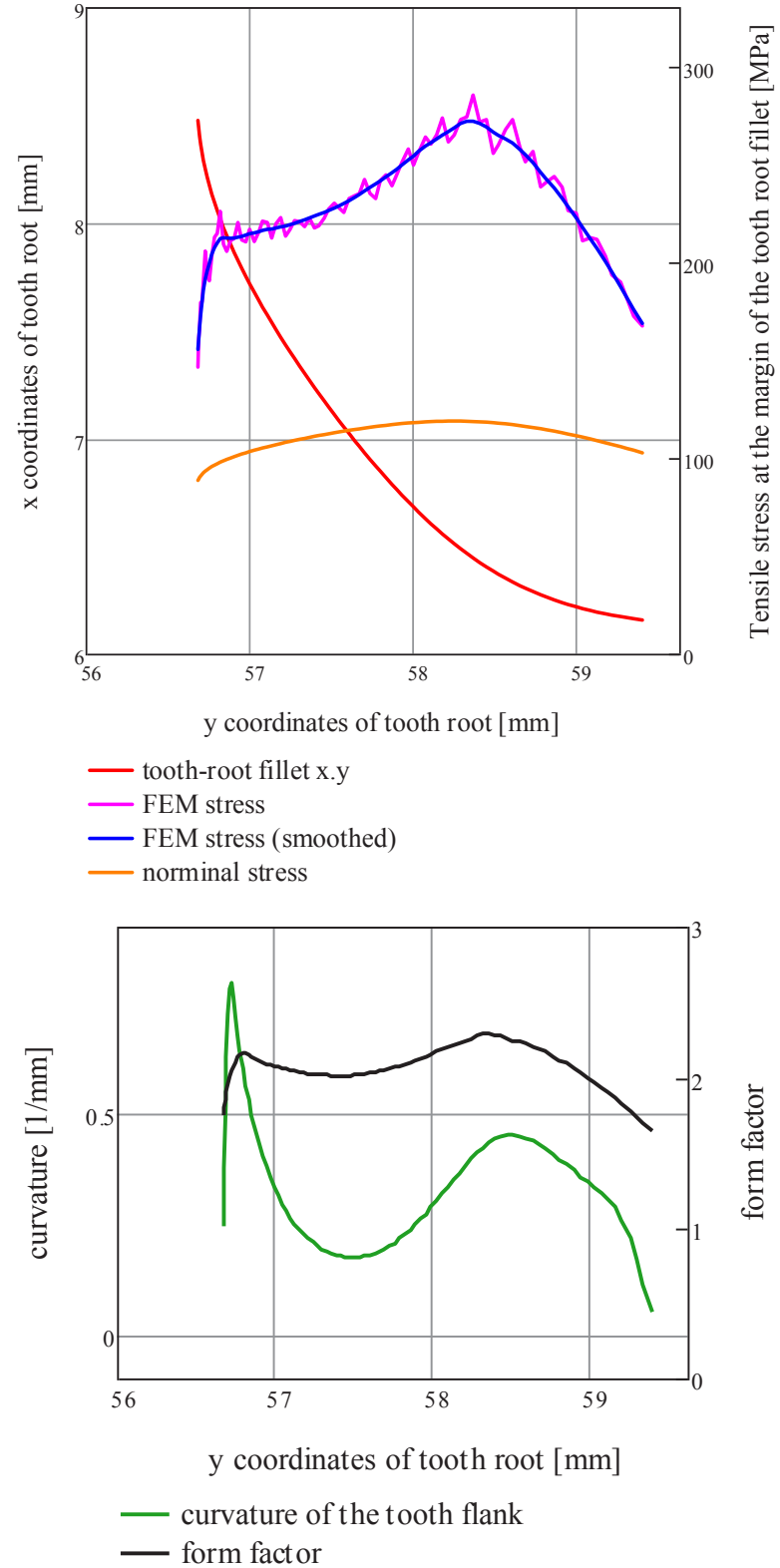

Fig. 16. Calculation results for a tooth root geometry.

Based on the curve shown in Figure 16 regarding the form factor and the curvature, a direct correlation can be recognized which is reflected in the other tooth root geometry. The comparison between the form factor and the curvature can be used to determine the following analytical equation 2, which allows a quick calculation of the maximum principal stresses at the margin based on the nominal stresses at the margin of a tooth root fillet geometry. Normally these maximum principal stresses are calculated by using computationally intensive FEanalyses. Following equation 2 can only be used within the tooth root fillet.

Formf $_{\text {new }}(y)=\operatorname{Formf}_{\operatorname{Ref}}(y) \cdot\left(\frac{\operatorname{Curv}_{0}+\operatorname{Curv}_{\text {new }}(y)}{\operatorname{Curv}_{0}+\operatorname{Curv}_{\operatorname{Ref}}(y)}\right)^{\zeta}$ (2)

In this equation, Formf new describes the new curve of the form factor along the $y$-coordinate of the tooth root fillet. A reference is determined from the results of the FE-calculations of the variants of the tooth root 
geometry described above (see Figure 15). This reference has the curve of the form factor Formf Ref $_{\text {and }}$ the curvature curv $_{\text {Ref, }}$, which is ideall to determine all other form factors which results from changed tooth root geometries and therefore new curves of curvature curv $_{\text {new. }}$. Curv $_{0}$ defines a reference value for the curvature which serves to avoid that the equation cannot be determined in specific points. The determination of the exponent $\zeta$ is done by using a routine, where the minimum deviation between the calculated and the FEM determined stresses can be found.

From the result shown in Figure 17, it is obvious that the stress curves achieved in this way correspond to the results of the computationally intensive FE-analyses. This applies in particular to the area of the tooth root fillet where the maximum tooth root stress value which is relevant for optimization occurs.

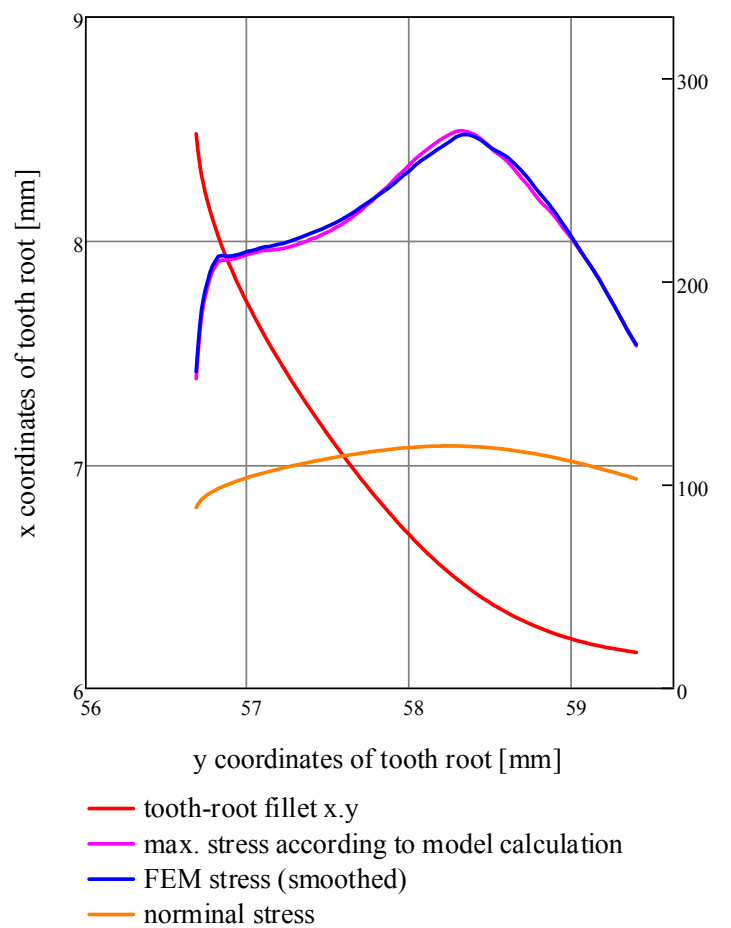

Fig. 17. Calculation results with analytical model approach for a tooth root geometry.

The analytical calculation model is used to determine the marginal stresses in the tooth root fillets of the many different gearwheels produced by different contours of the hob tip corner. For this purpose, the parameters of the Bézier-curve to describe the tip corner of the hob are randomly varied in a small range. To find a good solution as quickly as possible, the definition of the range around which the parameters will vary is based on the results of optimizations already performed, saved in databases. The variant with the lowest maximum marginal stresses will be used as the basis for a second optimization run. Therefore, the FE-calculation of the intermediate solution as well as the readjustment of the analytical equation is performed. Within the second optimization loop the hob tip contours are varied in an even smaller range around the intermediate solution. The result of the second optimization loop represents the best hob and tooth root geometry that produces minimal tooth root stress. A final FE-calculation is performed to compare the basic state with the optimized geometry. This contour leads to an almost constant marginal stress in the tooth root fillet (see Figure 18). The tooth geometry before and after the optimization only deviates in a range of about $m_{n} / 100$ to $m_{n} / 30 . m_{n} / 100$ is in the order of conventional flank corrections. The curves of the form factors and the curvatures before and after optimization shown in Figure 18 illustrate once again how strongly these two parameters influence each other.
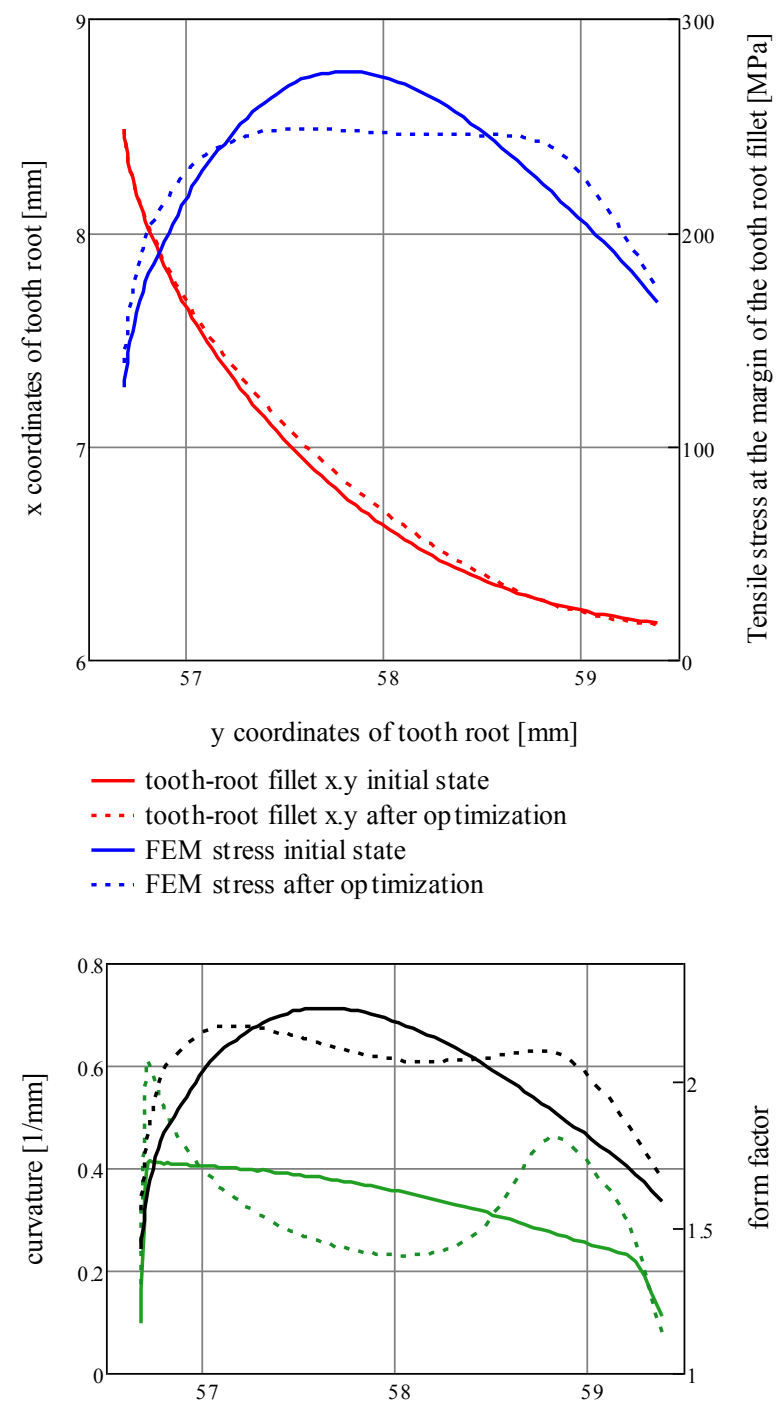

$\mathrm{y}$ coordinates of tooth root $[\mathrm{mm}]$

- curvature of the tooth flank of initial state

- - curvature of the tooth flank after op timization

— form facor initial state

.. - form factor after op timization

Fig. 18. Comparison of the results of the basic state with the optimized geometry.

The procedure for performing an optimization described above currently needs less than 7 minutes of computing time by using a laptop with an I7-processor. Thereby optimization potentials are achieved at a level as described in other research projects. On average the maximum tooth root stress can be reduced by $10 \%$ or more. 


\section{Conclusion and outlook}

In the context of this paper, a time-efficient method was presented which enables an optimization of the hob with regard to the reduction of the tooth root stresses of spur gears. In the case presented, the maximum marginal stress at the tooth root of an example spur gear could be reduced by approximately $17 \%$ within a calculation time of only a few minutes. This was possible by optimizing the tip corner contour of the hob and exploiting the tooth root fillet up to the active root diameter $d_{N f}$.

In order to achieve such an optimization potential in such a short computing time, several methods have been demonstrated in the context of this paper, which are applied within the presented optimization process. These include performing a quick hobbing simulation in order to determine the resulting tooth flank geometry using an adapted hob contour.

Furthermore, computing time can be reduced if the mesh required for the execution of FE-calculations does not always have to be regenerated but, as shown above, is adapted on basis of a good reference mesh. Additionally, an analytical equation for the description of form factors can be derived from the execution of only a few FE-calculations. With this equation, it is possible to calculate the maximum main stresses occurring in the tooth root from the nominal stress curves. This procedure proves to be much faster than the execution of many time-consuming FE-calculations.

By implementing additional steps, the computing time of the optimization method presented can be further reduced in the future. This includes the constant growth of a database that saves optimization results that have already been performed and thus provides starting solutions for finding the optimum geometry of new gearwheels or tools faster. Such a database also allows less FE-calculations to be required to determine the parameters for defining the analytical equation used in the optimization process.

\section{References}

1. H. Jahnbein, Einfluss der Korngröße, des Reinheitsgrades und der Kernhärte auf die Zahnfußtragfähigkeit von großen Zahnrädern, Dissertation Ruhr-Universität Bochum, Bochum (2015)

2. S. Schurer, Tragfähigkeitsgewinn im Zahnfuß durch hochreine Stähle, FVA-Nr. 293 III, FVA-Kurztitel: Späte Zahnfußbrüche/Reinheitsgrad, FVA-Heft Nr. 1148, Abschlussbericht, Frankfurt/Main (2015)

3. N. Bretl, Zahnfußbruch mit Rissausgang unter der Oberfläche an einsatzgehärteten Zahnrädern, FVANr. 293 II, FVA-Kurztitel: Späte Zahnfußbrüche, FVA-Heft Nr. 851, Abschlussbericht, Frankfurt/Main (2008)

4. H. Schaltmeier, Zahnfußtragfähigkeitssteigerung durch optimiertes Schleifen der Zahnfußausrundung, FVA-Nr. 306, FVA-Kurztitel: Profilschleifen / Zahnfußtragfähigkeit, FVA-Heft Nr. 619, Abschlussbericht, Frankfurt/Main (2000)
5. S. Rösch, B. Clausen, Thermochemisches Verfahren zur wirtschaftlichen Oberflächenbehandlung von großen Bauteilen, FVA-Nr. 454 I, FVA-Kurztitel: Carbonitrieren, FVA-Heft Nr. 855, Abschlussbericht, Frankfurt/Main (2008)

6. S. Lombardo, M. Steinbacher, Carbonitrieren von verzahnten Getriebebauteilen, FVA-Nr. 513 I, FVAKurztitel: Carbozahn, FVA-Heft Nr. 970, Abschlussbericht, Frankfurt/Main (2011)

7. O. Brömsen, Steigerung der Zahnfußtragfähigkeit von einsatzgehärteten Stirnrädern durch rechnerische Zahnfußoptimierung, Dissertation RWTH Aachen, Aachen (2005)

8. T. Frühe, Berechnung und Minimierung der Zahnfußspannung von Standard- und LowLossVerzahnungen, Dissertation Technische Universität München, München (2012)

9. Z. Roth, J. Opferkuch, High Load capacyty Gear Root Fillet Countour with a Bézier Curve, Tagungsband der Int. Conf. on Gears, München (2017)

10. C. Brecher, M. Brumm, J. Pollaschek, Optimierung der Zahnfußgeometrie von Stirnrädern durch den Einsatz FE-basierter Optimierungsmodelle im Verbund mit der Zahnkontaktanalyse, Tagungsband zum 12. Gemeinsamen Kolloquium Konstruktionstechnik 2014, Bayreuth (2014)

11. J. Polaschek, D. Billenstein, Einfluss der Zahnfußkontur auf die Zahnfußbeanspruchung, FVA-Nr. 709 I, FVA-Kurztitel: Freie Zahnfußgeometrie, FVA-Heft Nr. 1194, Abschlussbericht, Frankfurt/Main (2016)

12. J. Polaschek, D. Billenstein, Automatisierte, fertigungsgerechte FE-Optimierung der Zahnfußtragfähigkeit, FVA-Nr. 709 II, FVAKurztitel: FE-Tragfähigkeitsoptimierung Zahnfuß, Sachstandsbericht, Frankfurt/Main (2018)

13. DIN 3990 Teil 3, Tragfähigkeitsberechnung von Stirnrädern - Berechnung der Zahnfußtragfähigkeit, Beuth Verlag, Berlin (1987)

14. ISO 6336-3, Calculation of load capacity of spur and helical gears - Part 3: Calculation of tooth bending strength, ISO copyright office, Geneva (2006)

15. DIN 3960, Begriffe und Bestimmungsgrößen für Stirnräder (Zylinderräder) und Stirnradpaare (Zylinderpaare) mit Evolventenverzahnung, Beuth Verlag, Berlin (1987)

16. DIN 867, Bezugsprofile für Evolventenverzahnungen an Stirnrädern (Zylinderrädern) für den allgemeinen Maschinenbau und den Schwermaschinenbau, Beuth Verlag, Berlin (1986)

17. DIN 3972, Bezugsprofile von Verzahnwerkzeugen für Evolventen-Verzahnungen nach DIN 867, Beuth Verlag, Berlin (1952) 